\title{
Research on Database Curriculum Group
}

\author{
Qin Huilin ${ }^{1}$ \\ ${ }^{1}$ School of Information, Beijing Wuzi University, \\ Beijing, China
}

\begin{abstract}
Based on current content and teaching of course "Database Principles", this article discusses the problems of building a curriculum group centered around this particular course, and aims to improve the teaching methods as well as to increase teaching efficiency of course by integrating knowledge modules and synthesizing experiment designs.
\end{abstract}

Keywords: Database; Integration; Building of curriculum group

\section{INTRODUCTION}

<Database Principles> is a main course which combines both theories and practices, and provides the basis for the writing and management of Information Systems, and it's an important basic course for Information Management and Information Systems as well as E-commerce. Considering the school's orientation, talent cultivation objectives and sources of students, the course is aimed to cultivate talents who are well-trained with the basic database theories, acquainted with the newest trends in database development, familiarized with the mainstream operation methods of DMS. The aim of this approach is accommodate the demand of information technology society for high-caliber management talents, which in turn will help the students to be more creative and comprehensive. Throughout the learning of this course, the students are expected to comprehensively master the basic principles of DMS as well as the methods for developing OS and system design, and to nurture students' ability to build DMS with creativity and solve problems by utilizing database analysis.

\section{Current Situation and Problems}

Currently, to facilitate the compatibility between the professional course settings and the demands for talent cultivation, different schools have made various at-tempts, among which, the commonly at-tempted methods are, adjusting professional course, reduce theory class hours, increase practical training. But these methods are of little avail, and they failed to close the gap between teaching objectives and results, for the following reasons:

\subsection{Current course lack effective integration}

Through the relative investigations and researches on the course setting of professional information management and information system database, we have found out, database technology is the one of the important directions for researches on information management and information systems, therefore it should also be the direction of employment seeking for our undergraduates. The teaching objects of "Database Principles" are the students in their latter half of sophomore year, in their previous learning, they have only been brought to contact with the basics, and have little professional knowledge, which makes it hard for them to combine what they've learned with their majors. So through the study of this course, the students are able to comprehend the characteristics of their major, and set goals for their learning, which can help set the foundations for future follow-up courses. But currently the problems of improper joint connection of course progresses and overlapping course contents still exist, which caused the students to be deficient in the ability to integrate the contents of different courses.

\subsection{Defects in synthetic experiment design}

Currently all the designs of experiment content in different courses are arranged in accordance to the teaching contents of different chapters in the course, this mode is only adaptable to the teaching of a single course, as it lacks the consistency of relative modules and knowledge points between courses, this deprive students the abilities to connect and penetrate the teaching contents of different courses, which in turn would makes it hard for them to master a synthesized knowledge system. Through the investigations and researches on previous graduates, it was found out that the course content cannot keep up with the new development in science and technology, and there are a considerably large gap between current education and industry practices, and if we cannot provide our students with a knowledge system of database technology that is concurrent with the prevailing trend, then we will fail to accommodate the demand for advanced talents of ap-plied database science. Therefore, the key topic of this article is to discuss how to effectively integrate the teaching contents regarding database that will lead to the solution of above mention problem.

\section{Solution}

Based on the majors of our school and the professional building objective, the study of information management and information system training programs has set the foundation of the proposed database curriculum building, in order to solve the conflicts of overlapping content between courses and lagging update of course content as well as 
insufficient class hours. There are 4 courses in this article being discussed, which are, "Data Structure", "Database Principles", "Database Development Tools" and "System Analysis and Design". Considering the current situation of Information Management and In-formation Systems majors of our school, the focus is laid on the research of curriculum group building method by combining theory and practice, and hope to formulate an enlarged class method of teaching information management and information system database, and to improve the results of these types of courses.

\subsection{Connotation of Curriculum Group Building}

Curriculum group building is the primary trend of class building reform in recent years, and it is the integration of relative courses which specifically targeted at an object of education. The connotation of curriculum group building manifests itself in two aspects, first is relevance. Curriculum group takes the logical relations of knowledge, methodology and problems between courses as its integration points, this is repeatedly reflected in the process of curriculum building, and can help facilitate the transfer of theory in actual teaching. Second is integration. Curriculum group building facilitate the integration of relative modules and knowledge points in different courses, and demonstrate the significance of one course in a curriculum group to another, which can help students better grasp the relationship between one course and another as well as the entire curriculum group.

\subsection{Characteristics of Database Curriculum Group Building}

A curriculum group is usually consisted of three or more courses, although there is a fairly compact relation between each course, but the teaching content must be nonredundant, and the courses' knowledge points must remain in contact yet independent, last but not least, the practical training phase should also be consistent and progressive.

The building of curriculum through integrating and planning of relative teaching content, it can maximize the learning of theory and practical knowledge at minimized costs, and transform the pursuit of rigorous and intact teaching content in one single course to an extensive overall optimization of the entire curriculum group, which would change the current teaching status of fragmented and closed courses to a well-planned, integrated curriculum group. And through reorganizing the faculty, optimizing course structure, updating course content, integrating teaching resources, improving utility effectiveness, these approaches will further improve the overall teaching standards and advance the students' qualities and practical ability to a new level, and ultimately realizing the perfect bonding of theory and practice.

\subsection{Course Status and Interrelations}

Normally, the course "Data Structure" is taught in the first semester of sophomore year, students in this phase have already mastered the basics of program designing (e.g. Language C). "Database Principles" involves much software knowledge and computer system software theories, the objective of learning this course is to get acquainted with the fundamental concepts of database management, and master the main functions and implementation strategies of commonly used database management systems, which would help students acquire the ability of system design and application, and apply the theories of database system design and optimization into practices. "Software Engineering" and "System Analysis and Design" are core courses with a high level of comprehensiveness and practicality in the professional training programs of Software major and Information Management major. Its goal is to enable students master the traditional and most updated ways of software development through learning and master the usual processes of project development and maintenance of software, and lay the practical foundations for future software engineering studies and employment.

\section{Curriculum Group Building centered on Database}

\subsection{Establishment of Curriculum}

Based on the planning of our major and subject science, we have researched the teaching schemes of information management major and information systems major, and established the status and functions of "Database Principles" as well as other relative courses in the entire professional training systems, and we've drawn the conclusion that merely strengthen the one single course is far from enough to build a better department, we must build an entire curriculum group system to optimize development and deepen reform of the department. And to ensure the rationalization of knowledge structure and optimization of overall set-ting through demonstrating interrelations between courses by building curriculum group.

This curriculum group takes "Database Principle" as its core course, and "Data Structure" as its advance course, emphasize on cultivating students' data processing abilities and abilities to establish algorithms for various data structure. Whereas the "System Analysis and De-sign" is a follow-up course which emphasizes on students' abilities to problem-shooting. The contents of these course are interrelated and have a strong intrinsic logicality, they all fall under the same skill set development category.

\subsection{Objectives of Database Curriculum Group Building}

First and foremost, the courses of Information Management and Information System Dept. should be able to realize the professional training objectives, one of the objectives is to cultivate the knowledge structure and practical abilities to accommodate the demands of society and economic 
development for database applications, which is the reason for establishing a database curriculum group for Information Management and Information System Dept., which aims to accelerate the process of cultivating professional attainment and abilities by focusing manpower and material resources on strengthen the research and building of database curriculum group with subject knowledge relevance, integrated contents and relative independent structures.

\subsection{Building of Database Curriculum Group Systems}

Three value orientations must be thoroughly considered when building data-base curriculum group: 1. Ensuring the students' posses sound and solid basic and practical knowledge structure through attaching importance on joint connection of different courses. 2. Lay the foundation for sustainable development of the students. 3. Nurture students' abilities for further studies.

The fundamental aspect of database principle and methodology study mainly consists of two courses: "Data Structure" and "Database Principle". The experiments of this aspect focuses mainly on validation experiments, and secondarily on design and synthesized type, whereas the major focus of this aspect is on corroborating fundamental theories, and further master basic principles and skills, as well as to cultivate students' innovative mentality, design capability and practical abilities.

The practical aspect of database development and maintenance mainly consists of two courses: "Database Development Tool" and "System Analysis and Design". Exploratory experiments enable student to choose for themselves the subjects they are interested in, as well as the development tools, and cultivate their abilities of selfeducation, design research, innovative thinking as well as analysis skills and problem-shooting skills

\section{Implementation Strategy of Curriculum Group Building}

\subsection{Consistency of Curriculum Group Textbook Selection}

To build a database curriculum group, one must consider thoroughly the consistency and systematic relativity of the preceding courses and follow-up courses when choosing the textbooks. Based on this principle, quality textbooks that are published with systematical relevance to the curriculum group are key priorities for the selection process, especially representative textbooks published domestically. Viewing from the standpoint of China's planning and arrangement of professional computer science textbook series, the proposed textbooks are sufficient for the needs of establishing a database course oriented curriculum group.

\subsection{Teaching Document Specification}

The teaching of curriculum group can give a strong boost to the overall quality education of Information Management Department, the systematical teaching of this curriculum group can cultivate students' logical thinking ability, creative thinking ability and system design ability. Emphasis must be laid on the closely jointed teaching between different courses. And in order to optimize the entire structure of this curriculum group, one must scatter, intersperse, integrate the main knowledge points into the teaching of courses. The setting of syllabus, and planning for course building of this curriculum group must be aimed at improving the students' knowledge, ability and quality. And the arrangement of content for both singular courses as well as the entire curriculum group system, must be categorized by knowledge structure modules, then confirm their interrelations to ensure the non-redundancy and inclusiveness of course content, and the con-tents have a natural logical relations which focuses both on principle theories as well as practical appliances.

\subsection{Enhance Practical Training, with Focus on Ability Cultivation}

The teaching of theory course should be aimed at cultivating database development and application abilities, and use "whether it's essential/sufficient" as benchmark. When the teaching of practice corresponds with theory teaching, this can be an advantageous complement to theory teaching, as students can deepen their understanding of theory knowledge through practice. It is also a good exercise and training on students' integrative competences by testing students' learning efficiency through course design.

\section{Conclusion}

The building of curriculum group has become a core topic of education management instrument reform for college and universities. A curriculum group based on database, can form closely connected course group with strong logical relation and a hierarchic knowledge structure, and through optimizing and integrating course content, bring forth a hierarchic course system, and a experimental teaching mode which can unite different facets of knowledge with theoretical teaching, to ensure the ratio of theory teaching versus practical teaching is close to $1: 1$, which will further improve the cultivation of students' skills and quality by enforcing a practical appliance oriented teaching mode. 


\section{References}

[1] WANG Xianghui, CUI Wei, XU Junli. Research on Database Course's Teaching Reformation Based on CDIO[J]. COMPUTER EDUCATION, pp. 38-41, 2011, (2).

[2] Hairong Xiao. Research about Curriculum Group of Database Series in Information Management and Information System[J]. COMPUTER ED-UCATION, pp.65-69, 2011, (18).

[3] Wang Ning, Xu Wei, Yu zhongqiang. Study on the Research Teaching Model in Course of Principles of
Database System[J]. COMPUTER ED-UCATION, pp.97-101,2011, (20).

[4] ZHOU Lin, SUN Xiao-yong. Design and Implementation of Course Group Teaching Platform Based on Knowledge Points[J]. COMPUTER ERA, pp.53-55, 2011, (4).

[5] NIU Liang, ZHANG Bao-you, LI Jian-feng. Discussion on the Structure System, Teaching Method and Evaluation System of the Database Application[J]. Higher Education Edition, pp.29-33, 2012, (4) 